\title{
EFFECT OF AN ADDITIVE ON THERMAL OUTPUT DURING ELECTROLYSIS OF HEAVY WATER WITH A PALLADIUM CATHODE $^{*}$
}

\author{
Q. WANG and J. DASH \\ Low Energy Nuclear Laboratory, Portland State University, Portland, OR 97207, USA
}

\begin{abstract}
A titanium additive to a heavy water-sulfuric acid electrolyte has been found to increase the thermal output during electrolysis with a palladium foil cathode. Eight runs, about six hours each, over a period of 16 days, gave an average of 1.8 watt excess thermal power output compared with a light water control cell. This is about twice the excess obtained in co-deposition experiments. The excess thermal power output ranged from $0.5 \pm 0.1 \mathrm{~W}$ to $2.6 \pm 0.1 \mathrm{~W}$, which was an average of about $17 \%$ more than the input power. The additive apparently catalyzes heat producing reactions on the surface of the palladium. After electrolysis, the $\mathrm{Pd}$ cathode contained localized surface concentrations of $\mathrm{Ag}, \mathrm{Ni}, \mathrm{Fe}, \mathrm{Ti}, \mathrm{S}$, and $\mathrm{Pt}$.
\end{abstract}

\section{Introduction}

During electrolysis of $\mathrm{D}_{2} \mathrm{O}-\mathrm{H}_{2} \mathrm{SO}_{4}$ electrolyte with a Ti cathode and a $\mathrm{Pt}$ anode, Ti erodes from the cathode and dissolves in the electrolyte ${ }^{1}$. When this electrolyte containing dissolved Ti was used for electrolysis with a Pd cathode and a Pt anode, enhanced excess heat was observed. Also, localized concentrations of unexpected elements were found on the surface of the Pd cathode. This report contains data on the variation of excess heat production with concentration of $\mathrm{Ti}$ in the electrolyte and on the variation of the magnitude of the excess thermal power over a period of 16 days. Data on the distribution of elements on the Pd cathode is also presented.

\section{Experimental methods and results}

The closed electrolysis cells and the excess heat calculation method used for this research were described previously ${ }^{2}$. Fig. 1 shows the circuit diagram used for electrolysis. A control cell with two Pt foil electrodes is connected in series with an experimental cell containing a Pt foil anode and a Pd foil ( $0.35 \mathrm{~mm}$ thick) cathode. The Pd was Alfa Aesar stock number 11514, 99.9\% Pd (metals basis). The as received thickness was $0.5 \mathrm{~mm}$. It was cold rolled to $0.35 \mathrm{~mm}$ thickness and then sheared to produce a cathode $23 \times 25 \mathrm{~mm}$. A one $\mathrm{mm}$ diameter Pt lead wire was then crimped to the $\mathrm{Pd}$ cathode through a hole which was punched in one end of the Pd. One mm diameter Pt lead wires were crimped to the Pt electrodes in the same way. The electrolyte in the control cell contained concentrated $\mathrm{H}_{2} \mathrm{SO}_{4}$ and deionized $\mathrm{H}_{2} \mathrm{O}$ in the ratio $1: 12.3$. The experimental cell electrolyte contained the same batch of concentrated $\mathrm{H}_{2} \mathrm{SO}_{4}$ and Aldrich

\footnotetext{
* This research was supported by a grant from the New York Community Trust.
} 
$\mathrm{D}_{2} \mathrm{O}$ (catalog number 34,716-7) in the ratio 1:6.7. The average current density on the $\mathrm{Pd}$ cathode was about $0.3 \mathrm{~A} / \mathrm{cm}^{2}$.

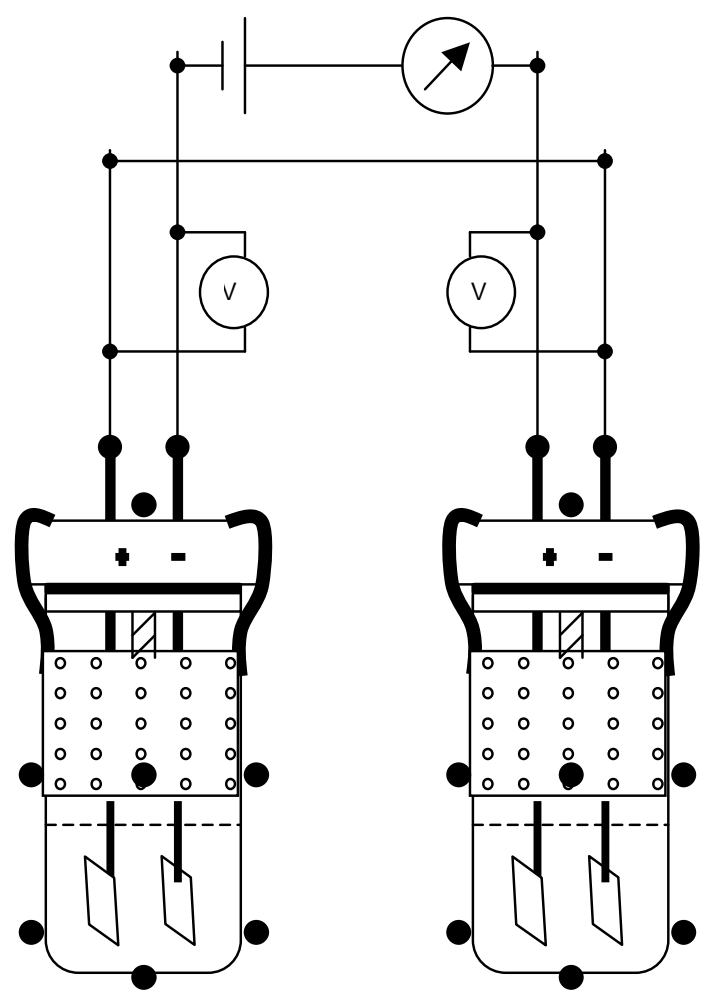

Figure 1 Circuit containing a constant current DC power supply and a control cell in series with an experimental cell. The black circles indicate the locations of eight thermocouples attached to the outside of each cell. The output of the thermocouples and the cell voltages were monitored with a computer. The cell temperature was then calculated as the arithmetic average of these eight readings.

Fig. 2 shows the effect of Ti additions to the experimental cell electrolyte on excess thermal power. Data points with no added Ti and with $0.002 \mathrm{~g} / \mathrm{ml}$ added Ti show that no excess heat was produced. After increasing the Ti content to $0.011 \mathrm{~g} / \mathrm{ml}$, two consecutive runs gave significant $(0.2$ and $0.4 \mathrm{~W})$ excess thermal power. At $0.022 \mathrm{~g} / \mathrm{ml} \mathrm{Ti}$ concentration, three runs gave 1.2, 0.7, and $1.0 \mathrm{~W}$ excess thermal power. At higher concentrations of $\mathrm{Ti}$, a Ti compound deposits on the cell wall.

Fig. 3 gives the excess heat results for eight consecutive runs with a new batch of electrolyte containing heavy water and sulfuric acid in the same ratio as before and with $0.024 \mathrm{~g} / \mathrm{ml}$ Ti added.

The data in Fig. 3 for six of the eight runs show that the calculated excess thermal power assuming no mass loss is almost the same as the results obtained when the mass loss is included in the calculations. For the 8/9 and 8/15 data, the control cell lost $\sim 1 \mathrm{~g}$ 
more mass than the experimental cell, and the calculated excess thermal power is not accurate. For the other runs, both cells lost less than $0.5 \mathrm{~g}$, and the calculated excess thermal power is thought to be accurate.

(3-23-05)-(5-9-05)

Excess thermal power vs. Ti content of the electrolyte

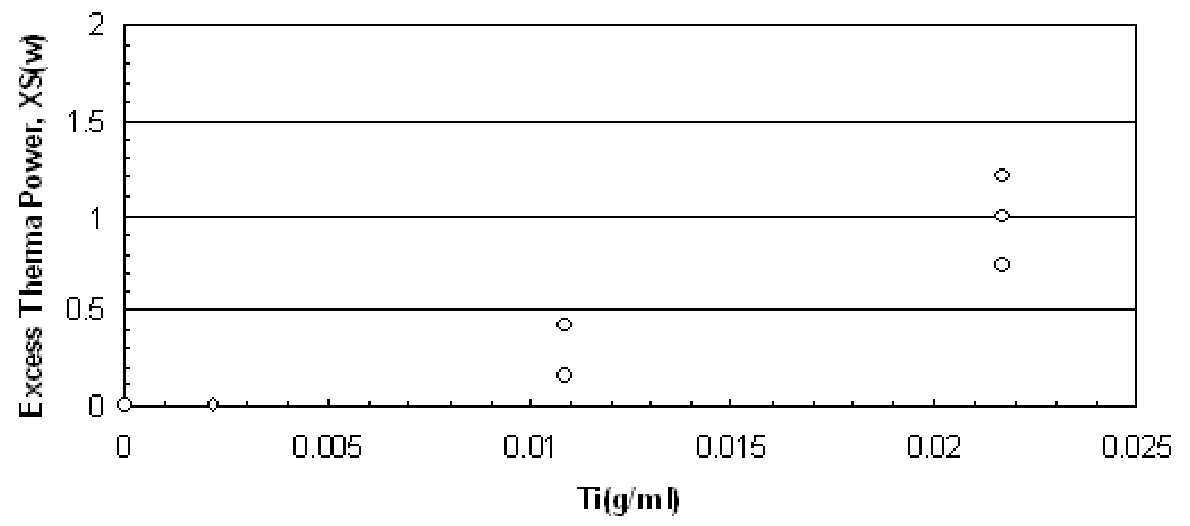

Figure 2. Excess heat approximately doubled after Ti content of the electrolyte was increased from $0.011 \mathrm{~g} / \mathrm{ml}$ to $0.022 \mathrm{~g} / \mathrm{ml}$. At higher concentrations of Ti, a Ti compound deposited on the cell wall.

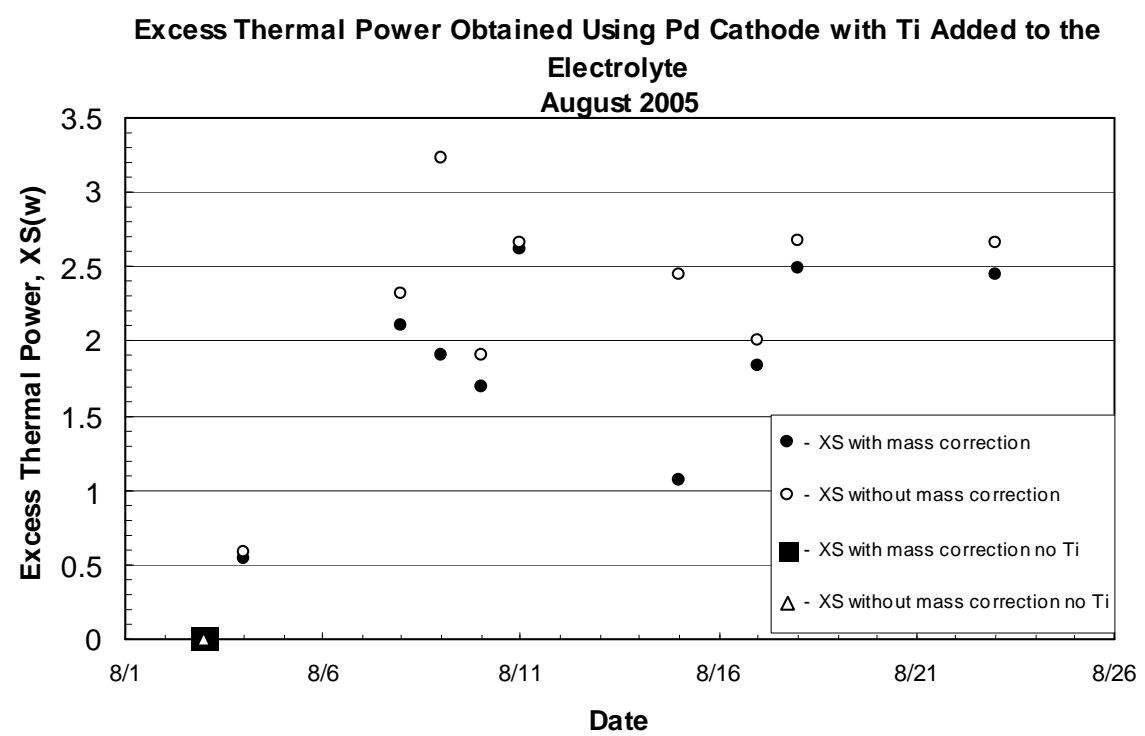

Figure 3. Excess thermal power with and without mass correction. Average excess is $1.8 \mathrm{~W}$. Mass correction was calculated in order to account for the loss of recombination heat due the escape of gases from the cells.

The Pd electrode used for the data in Fig. 3 was examined with a scanning electron microscope equipped with an energy dispersive spectrometer. Characteristic x-ray spectra were taken from each of the rectangles, on both the concave and the convex sides shown in Fig. 4. 


\begin{tabular}{|c|c|c|c|}
\hline 0.64 & 0.2 & 0.08 & 0.15 \\
\hline 0.71 & 0.14 & 0.05 & 0.12 \\
\hline 0.61 & 0.07 & 0.01 & 0.05 \\
\hline 0.69 & 0 & 0 & 0.03 \\
\hline 0.68 & 0.06 & 0.02 & 0.02 \\
\hline 0.59 & 0.02 & 0.02 & 0.02 \\
\hline 0.26 & 0.02 & 0.02 & 0.01 \\
\hline
\end{tabular}

Figure 4a. Side facing anode (concave). counts
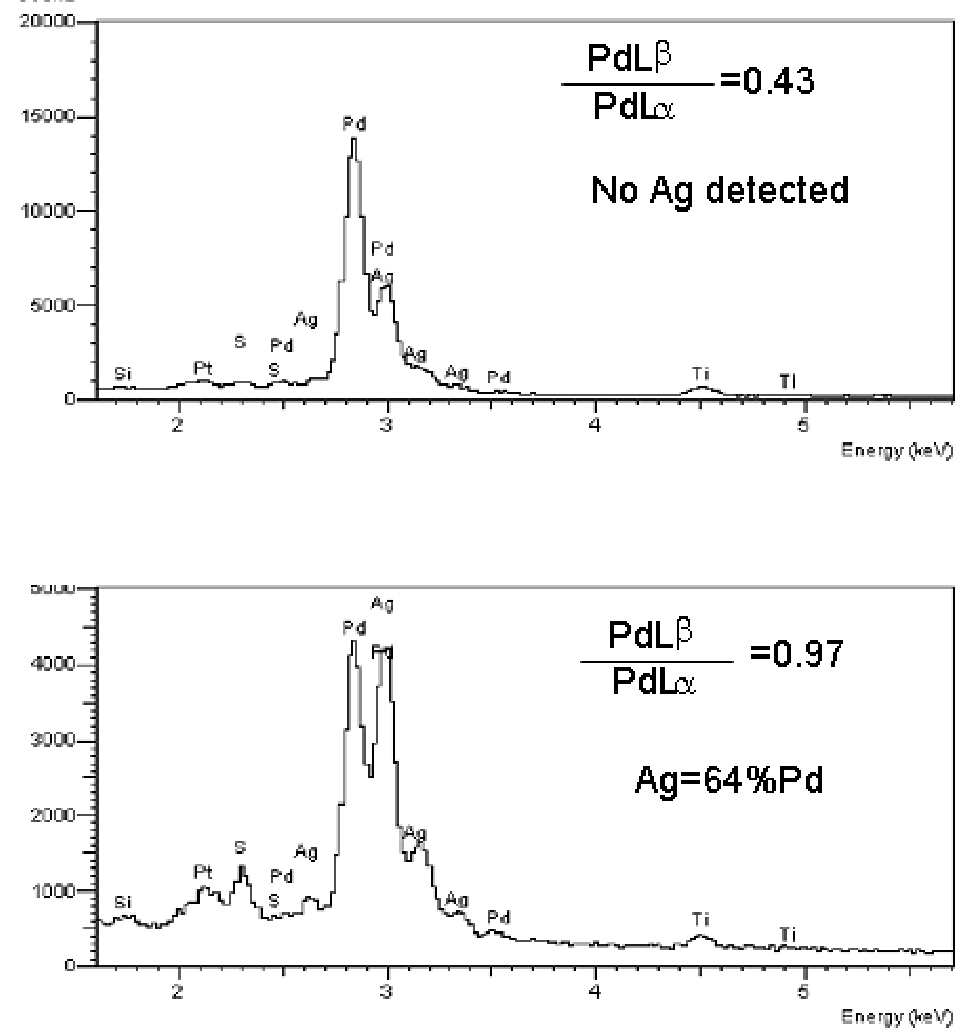

Figure 5. The upper spectrum was taken from the rectangle on the left side of center in Fig. 4a, and the lower spectrum was taken from the rectangle in the upper left corner of Fig. 4a.

Fig. 4 shows light microscope photographs of the two sides of the Pd cathode from which excess heat reported in Fig. 3 was obtained. The electrode is approximately $2.3 \mathrm{~cm}$ 
wide and $2.5 \mathrm{~cm}$ high. The EDS spectra were obtained by scanning the area in each rectangle. Examples of the spectra are shown in Fig.5.

The upper spectrum in Fig. 5 was taken from the rectangle on the left of center in Fig. $4 \mathrm{a}$, and the lower spectrum in Fig. 5 was taken from the rectangle in the upper left corner of Fig. 4a. Both spectra have predominant Pd L $\alpha$ peaks at $2.84 \mathrm{keV}$, but the Pd L $\beta$ peak at $2.99 \mathrm{keV}$ is far more intense in the lower spectrum than in the upper spectrum. The expected intensity ratio, $P d L \beta / L \alpha$, is $0.42^{3}$, whereas this ratio in the upper spectrum is 0.43 , and it is 0.97 in the lower spectrum. A possible explanation for this difference is that $\mathrm{Ag}$, which has its $\mathrm{L} \alpha$ peak at $2.98 \mathrm{keV}$, is present at some locations on the Pd cathode after electrolysis, as proposed previously ${ }^{4}$. Further evidence to support this suggestion is that the $\mathrm{Ag} \mathrm{L} \beta$ peak at $3.15 \mathrm{keV}$ is fully developed in the lower spectrum, but it is not prominent in the upper spectrum.

ISIS deconvolution software was used to determine the ratio $\mathrm{Ag} / \mathrm{Pd}$ for each of the rectangles in Fig. 4. This ratio was 0.64 for the lower spectrum and zero for the upper spectrum in Fig. 5. The number on each rectangle is the ratio $\mathrm{Ag} / \mathrm{Pd}$ for that area. For example, the number 0.64 for upper left corner, concave side, tells us that the number of $\mathrm{Ag}$ atoms is $64 \%$ of the number of Pd atoms in that area. The concave side faced the anode during electrolysis. The silver is concentrated near the left edge of the concave side. Ag was not detected in two rectangles near the center of the concave side. No high concentrations of Ag were found on the convex side of the Pd electrode.

\section{Discussion}

The addition of about $0.02 \mathrm{~g} / \mathrm{ml}$ of Ti to the electrolyte enhances the output of excess thermal power, and also improves reproducibility. The mechanisms which produce these effects are not known. However, Ti is known to have catalytic properties ${ }^{5}$. It may be that a complex of Ti deposits on the Pd cathode and activates sites which would otherwise remain dormant. The spectra in Fig. 5 both have small Ti peaks, which probably result from the deposition of a Ti complex. In addition to $\mathrm{Pd}, \mathrm{Ag}$, and $\mathrm{Ti}$, the lower spectrum in Fig. 5 contains appreciable amounts of $\mathrm{S}, \mathrm{Fe}, \mathrm{Ni}$, and Pt. These elements are not detected in the upper spectrum of Fig. 5. S and Pt most likely are deposited from the electrolyte. The origin of $\mathrm{Fe}$ and $\mathrm{Ni}$ is not known. It is unlikely that these elements were present in appreciable amounts in the electrolyte.

\section{References}

1. J. Warner and J. Dash, Proc. ${ }^{\text {th }}$ Int. Conf. on Cold Fusion; SIF Conf. Proc., Vol. 70, F. Scaramuzzi (Ed.), Bologna, 2000, p. 161.

2. J. Dash and A. Ambadkar, Proc. $11^{\text {th }}$ Int. Conf. on Cold Fusion, Marseille, France, 2004, p. 477.

3. G. G. Johnson, Jr., and E. W. White, American Society for Testing and Materials Data Series DS 46, 1970.

4. J. Dash, G. Noble, and D. Diman, Trans. Fusion Technology 26, 299 (1994).

5. J. Liu, Y. Yu, Y. Li, H. He, H. Tan, and K. Xu, Chemical Abstracts 131, 1303 (1999). 